\title{
COMPUTATIONAL STUDY ON STRUCTURE AND PROPERTIES OF NEW ENERGETIC MATERIAL 3,7-BIS(DINITROMETHYLENE)-2,4,6,8-TETRANITRO-2,4,6,8-TETRAAZA-BICYCLO[3.3.0]OCTANE
}

\author{
Xinghui Jin*,a, Jianhua Zhou, ${ }^{a}$ Shijie Wang ${ }^{\mathrm{a}}$ and Bingcheng $\mathrm{Hu}^{\mathrm{b}}$ \\ ${ }^{a}$ School of Chemistry and Pharmaceutical Engineering, Qilu University of Technology, Jinan 250353, China \\ ${ }^{\mathrm{b}} \mathrm{S}$ chool of Chemical Engineering, Nanjing University of Science and Technology, Nanjing, 210094, China
}

Recebido em 13/11/2015; aceito em 08/01/2016; publicado na web em 28/03/2016

\begin{abstract}
The IR spectrum, crystal structure, electronic structure, thermodynamic properties, heat of formation and detonation properties of a new polynitro heterocyclic energetic material 3,7-bis(dinitromethylene)-2,4,6,8-tetranitro-2,4,6,8-tetraazabicyclo[3.3.0]octane were investigated theoretically. The calculated results show that this compound has a centrosymmetric structure and the molecular packing prediction indicates that the crystalline packing of the title compound is $P 2_{1} 2_{1} 2_{1}$ and the corresponding cell parameters are as follows: $Z=4, a=22.03 \AA, b=8.73 \AA, c=8.42 \AA, \alpha=90^{\circ}, \beta=90^{\circ}$ and $\gamma=90^{\circ}$. Based on the high positive heat of formation (HOF, $740.4 \mathrm{~kJ} \mathrm{~mol}^{-1}$ ), excellent detonation properties (detonation velocity $D, 9.77 \mathrm{~km} \mathrm{~s}^{-1}$; detonation pressure $P, 45.9 \mathrm{GPa}$ ), energy gap $\left(\Delta E_{\text {LUмо-номо }}\right)$ $4.19 \mathrm{eV}$ and the molecular electrostatic potentials (MEP), it is predicted that 3,7-bis(dinitromethylene)-2,4,6,8-tetranitro-2,4,6,8tetraazabicyclo[3.3.0] octane could be may be a superior high-energy density compound (HEDC) to RDX and HMX.
\end{abstract}

Keyword: density functional theory; heat of formation; energetic properties; electronic structure; crystal structure.

\section{INTRODUCTION}

Poly-nitro compounds continue to attract considerable interest for their wide applications in propellants, explosives and pyrotechnics. ${ }^{1-4}$ Therefore, the design and synthesis of new HEDMs with high performance properties has been one of the most challenging tasks in this field. For instance, from the original well-known explosives 1,3,4,6-tetranitroglycouril (TNGU, Figure 1, A), ${ }^{5}$ hexahydro-1,3,5-trinitro-1,3,5-triazine (RDX) ${ }^{6}$ and 1,3,5,7-tetranitro-1,3,5,7-tetraazacyclooctane $(\mathrm{HMX})^{7}$ to the present popular explosives 2,4,6,8,10,12-hexanitro-2,4,6,8,10,12-hexaazaisowurtzitane (CL20), ${ }^{8}$ cis-2,4,6,8-tetranitro-1H,5H-2,4,6,8-tetraazabicyclo[3.3.0] octane (Bicycle-HMX), ${ }^{9}$ 1,1-diamine-2,2-dinitroethene (FOX-7, Figure 1, B), ${ }^{10}$ etc., they are all HEDMs with high positive heats of formation (HOFs) and superior detonation performances $(D$, detonation velocity and $P$, detonation pressure). However, in most cases, the requirements of high detonation velocity and detonation pressure are often contradictory to their physical properties such as thermal and hydrolytic stability, sensitivity toward heat, shock, friction and electrostatic discharge, positive oxygen balance, environmentally benign decomposition products, low cost and so on. ${ }^{11}$ Take TNGU for example, it is moisture sensitive though its detonation performances are superior to those of RDX and HMX. Because there are four nitro groups in the molecule which will improve the heat of formation, while the carbonyl groups located at the end of the molecule makes it decompose easily under moisture. Research also reported that $\mathrm{C}=\mathrm{C}-$ group is more stable than $-\mathrm{C}=\mathrm{O}$ or $-\mathrm{N}=\mathrm{N}$-group and thus, a new patent structure $\mathrm{C}_{6} \mathrm{H}_{10} \mathrm{~N}_{4}$ (Figure 1, C) was designed.

On the other hand, five-membered nitrogen-rich heterocycles are potential candidates for traditional energetic materials. In this structure, there are four N-H bonds in the ring and four $\mathrm{C}-\mathrm{H}$ bonds at the end of the ring which can be replaced by additional functional groups such as nitro, isocyano, azido functional groups and so on. The main difference between the nitro, isocyano, and azido functional groups is that when adding a nitro substituent into a molecule, it can improve the detonation properties of the compound more effectively

*e-mail: jingetiema0000@126.com than adding either isocyano or azido groups. ${ }^{12}$ Herein, a new high-energy density material 3,7-bis(dinitromethylene)-2,4,6,8-tetranitro-2,4,6,8-tetraazabicyclo[3.3.0] octane (Figure 1, D) was designed on the basis of the structure of TNGU and FOX-7.

All computational details were performed on Gaussian 03 package ${ }^{13}$ with the density functional theory (DFT) ${ }^{14,15}$ at B3LYP method ${ }^{16,17}$ with 6-31G $(d, p)$ basis set. ${ }^{18,19}$ Vibrational analyses at the same level of theory were performed to confirm that all of the optimized structures correspond to be the local energy minima on the potential energy surfaces. Meanwhile, natural bond orbital (NBO) analysis ${ }^{20}$ was carried out to investigate the trigger bond. All the calculations were performed using the default convergence criteria in the programs.

Calculation of the HOF of a new energetic material is necessary since it plays an important role in the detonation properties. To obtain the accurate HOF values, isodesmic reactions should be designed (Figure 2) in which the electronic environment of atoms in the reactants and products are very similar in isodesmic reactions, the errors of electronic correction energies can be counteracted, and then the errors of the calculated HOFs can be greatly reduced. The principle to design an isodesmic reaction is that the number of the atoms and the type of the bonds should be the same on both sides of the reaction. Previous studies also demonstrated this method as a feasible approach in estimation accurate of HOFs of new energetic materials. ${ }^{21,22}$

The HOF for the title compound at $298 \mathrm{~K}$ was derived from the following isodesmic reaction (Figure 2):

For the isodesmic reaction, the HOF can be calculated from the following equation:

$$
\Delta H_{298 \mathrm{~K}}=\sum \Delta H_{\mathrm{f}, \mathrm{p}}-\sum \Delta H_{\mathrm{f}, \mathrm{R}}
$$

where $\Delta H_{\mathrm{f}, \mathrm{p}}$ and $\Delta H_{\mathrm{f}, \mathrm{R}}$ are the HOFs of the products and reactants at $298 \mathrm{~K}$, respectively. On the other hand, the HOF of a compound at $298 \mathrm{~K}$ can also be defined as follows:

$\Delta H_{298 \mathrm{~K}}=\Delta E_{298 \mathrm{~K}}+\Delta(P V)=\Delta E_{0}+\Delta \mathrm{ZPE}+\Delta H_{\mathrm{T}}+\Delta n R T$

where $\Delta E_{298 \mathrm{~K}}$ and $\Delta E_{0}$ are the change in total energy between the products and reactants at $298 \mathrm{~K}$ and $0 \mathrm{~K}$, respectively; $\triangle \mathrm{ZPE}$ is the 
<smiles>O=C1N([N+](=O)[O-])C2C(N1[N+](=O)[O-])N([N+](=O)[O-])C(=O)N2[N+](=O)[O-]</smiles>

A<smiles>NC(N)=C([N+](=O)[O-])[N+](=O)[O-]</smiles>

B<smiles>C=C1NC2NC(=C)NC2N1</smiles>

C<smiles>O=[N+]([O-])OC(=C1N([N+](=O)[O-])C2C(N1[N+](=O)[O-])N([N+](=O)[O-])C(=C([N+](=O)[O-])[N+](=O)[O-])N2[N+](=O)[O-])C([N+](=O)[O-])=[N+]([O-])[O-]</smiles>

$\mathrm{D}$

Figure 1. Structures of the related compounds<smiles>O=[N+]([O-])C(=C1N([N+](=O)[O-])C2C(N1[N+](=O)[O-])N([N+](=O)[O-])C(=[N+]([O-])[O-])N2[N+](=O)[O-])[N+](=O)[O-]</smiles>

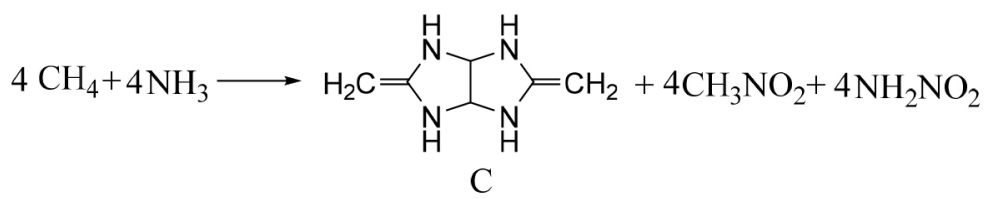

Figure 2. Isodesmic reaction designed for the title compound

difference between the zero-point energy (ZPE) of the products and reactants; and $\Delta H_{\mathrm{T}}$ is the thermal correction from 0 to $298 \mathrm{~K}$. For reactions in the gas phase, $\Delta(P V)$ equals $\Delta n R T$, and for isodesmic reactions, $\Delta n=0$. Based on equation (1) and (2), the HOF of the title compound can be easily obtained.

The experimental HOFs of the reference compounds $\mathrm{NH}_{3}, \mathrm{CH}_{4}$, $\mathrm{NH}_{2} \mathrm{NO}_{2}$ and $\mathrm{CH}_{3} \mathrm{NO}_{2}$ are available. However, the experimental HOF of compound $\mathbf{C}$ is unavailable and the additional calculations for the atomization reaction $\mathrm{C}_{6} \mathrm{H}_{10} \mathrm{~N}_{4} \rightarrow 6 \mathrm{C}(\mathrm{g})+10 \mathrm{H}(\mathrm{g})+4 \mathrm{~N}(\mathrm{~g})$, must be carried out to accurately predict its HOF. It should be pointed out that the complete basis set CBS-Q method has been verified to be able to predict the HOFs accurately. Therefore, this method was used in this work to obtain the accurate HOF of compound C $\left(345.2 \mathrm{~kJ} \mathrm{~mol}^{-}\right.$ $\left.{ }^{1}\right)$. Then HOF of the title compound was extracted easily while the HOFs of all the reference compounds were known.

Since the phase of most energetic compounds is solid, the HOFs for such compounds requires solid-phase HOFs $\left(\Delta H_{\mathrm{f}, \text { solid }}\right)$ rather than gas-phase HOFs $\left(\Delta H_{\mathrm{f}, \text { gas }}\right)$. According to Hess' law, ${ }^{23}$ the $\Delta H_{\mathrm{f}, \text { solid }}$ can be obtained from the $\Delta H_{\mathrm{f}, \mathrm{gas}}$ and heat of sublimation $\left(\Delta H_{\text {sub }}\right)$ :

$$
\Delta H_{\mathrm{f}, \text { solid }}=\Delta H_{\mathrm{f}, \mathrm{gas}}-\Delta H_{\mathrm{sub}}
$$

where $\Delta H_{\text {sub }}$ denotes the heat of sublimation.

Recently, Politzer et al..$^{24}$ proposed that the $\Delta H_{\text {sub }}$ of energetic compounds correlates well with the molecular surface area and electrostatic interaction index $\left(v \sigma_{t o t}\right)$.The empirical expression of the approach is as follows:

$$
\Delta H_{\text {sub }}=a A^{2}+b\left(v \sigma_{t o t}^{2}\right)^{0.5}+c
$$

where $A$ is the surface area of the $0.001 \mathrm{e} \mathrm{bohr}^{-3}$ isosurface for the electronic density of the molecule; $v$, the degree of balance between the positive and negative potentials on the isosurface; $\sigma_{t o t}^{2}$ is a measure of the variability of the electrostatic potential on the molecular surface; the coefficients $a, b$, and $c$ were determined to be $a=2.670$ $\times 10^{-4} \mathrm{kcal} \mathrm{mol}^{-1} \mathrm{~A}^{-4}, b=1.650 \mathrm{kcal} \mathrm{mol}^{-1}$, and $c=2.966 \mathrm{kcal} \mathrm{mol}^{-1}$. This approach has been demonstrated to be a reliable and popular approach to predict the heats of sublimation of energetic materials.

The detonation velocity $(D)$ and detonation pressure $(P)$ were calculated by the empirical Kamlet-Jacobs equations: $:^{25}$

$$
\begin{gathered}
D=1.01\left(N \bar{M}^{0.5} Q^{0.5}\right)^{0.5}(1+1.3 \rho) \\
P=1.558 \rho^{2} N \bar{M}^{0.5} Q^{0.5}
\end{gathered}
$$

where $\rho$ is the loaded density of the explosive $\left(\mathrm{g} \mathrm{cm}^{-3}\right) ; D$, the detonation velocity $\left(\mathrm{km} \mathrm{s}^{-1}\right) ; P$, the detonation pressure (GPa); $N$ is the number of moles of detonation gases per-gram explosive $\left(\mathrm{mol} \mathrm{g}^{-1}\right)$; $\bar{M}$ is the average molecular weight of these gases $\left(\mathrm{g} \mathrm{mol}^{-1}\right)$; and $Q$ is the heat of detonation $\left(\mathrm{cal} \mathrm{g}^{-1}\right)$. For known explosives, their $Q$ and $\rho$ can be measured experimentally; thus their $D$ and $P$ can be calculated according to Kamlet-Jacobs equations. However, for new compounds, their $Q$ and $\rho$ cannot be evaluated from experimental measures and therefore, to estimate their $D$ and $P$, we first need to calculate their $Q$ and $\rho$ according to Table 1 and Monte-Carlo method, respectively.

Additionally, Politzer et al. ${ }^{26}$ found that the results for $\rho$ obtained using this method may have some errors for some systems, epecially in which there are strong hydrogen bonds. Thus, the $\rho$ of CHNO energetic materials should be corrected using the following equation to give an accurate result:

$$
\rho=\beta_{1}\left(\frac{M}{V}\right)+\beta_{2}\left(v \sigma_{t o t}^{2}\right)+\beta_{3}
$$

where $v$ is the degree of balance between the positive and negative potentials on the isosurface; $\sigma_{\text {tot }}^{2}$ is a measure of the variability of the electrostatic potential on the molecular surface; and the coefficients $\beta_{1}, \beta_{2}$, and $\beta_{3}$ are $0.9183,0.0028$, and 0.0443 , respectively.

Table 1. Formulas for calculating the values of $N, M$, and $Q$ for an explosive $\mathrm{C}_{a} \mathrm{H}_{b} \mathrm{O}_{c} \mathrm{~N}_{d}$

\begin{tabular}{lccc}
\hline \multirow{2}{*}{ Parameters } & \multicolumn{3}{c}{ Stoichiometric ratio } \\
\cline { 2 - 4 } & $\mathrm{c} \geq 2 \mathrm{a}+\mathrm{b} / 2$ & $2 \mathrm{a}+\mathrm{b} / 2>\mathrm{c} \geq \mathrm{b} / 2$ & $\mathrm{~b} / 2>\mathrm{c}$ \\
\hline$N$ & $(\mathrm{~b}+2 \mathrm{c}+2 \mathrm{~d}) / 4 M$ & $(\mathrm{~b}+2 \mathrm{c}+2 \mathrm{~d}) / 4 M$ & $(\mathrm{~b}+\mathrm{d}) / 2 M$ \\
$Q^{* 10^{-3}}$ & $4 M /(\mathrm{b}+2 \mathrm{c}+2 \mathrm{~d})$ & $(56 \mathrm{~d}+88 \mathrm{c}-8 \mathrm{~b}) /(\mathrm{b}+2 \mathrm{c}+2 \mathrm{~d})$ & $(2 \mathrm{~b}+28 \mathrm{~d}+32 \mathrm{c}) /(\mathrm{b}+\mathrm{d})$ \\
\hline
\end{tabular}

${ }^{\mathrm{a}} \mathrm{a}, \mathrm{b}, \mathrm{c}$ and $\mathrm{d}$ stand for the number of $\mathrm{C}, \mathrm{H}, \mathrm{O}$ and $\mathrm{N}$ atoms in the explosive molecule respectively; ${ }^{\mathrm{b}} \mathrm{M}$ in the formula is the molecular weight of the explosive $\left(\mathrm{g} \mathrm{mol}^{-1}\right) ; \Delta H_{\mathrm{f}}$ is the heat of formation of the explosive $\left(\mathrm{kJ} \mathrm{mol}^{-1}\right)$. 
Since the high-energy density compounds are usually in solid phases, the possible polymorphs and crystal structure of the title compound were predicted using polymorph module of Materials Studio. The COMPASS force field is capable of predicting the condensed phase properties by searching the possible molecular packing among the most probable seven space groups $\left(P 2_{1} / c, P-1, P 2_{1} 2_{1} 2_{1}\right.$, $P b c a, C 2 / c, P 2_{1}$ and $P n a 2_{1}$ ).

\section{RESULTS AND DISCUSSION}

\section{Molecular geometrical structures}

Figure 3 shows the optimized structure of the title compound at the B3LYP/6-31G $(d, p)$ level. The selected bond length, bond angle and dihedral angle of the title compound that calculated at the same level were also presented in Table 2. From the table, it is seen that all the $\mathrm{C}-\mathrm{N}$ bond lengths of the title compound range from 1.3937 to $1.4856 \AA$. They were between normal $\mathrm{C}-\mathrm{N}$ bond length $(1.49 \AA)$ and the normal $\mathrm{C}=\mathrm{N}$ bond length $(1.28 \AA)$ which indicates that the $\mathrm{C}-\mathrm{N}$ bond lengths in the molecule tend to be average and form a large conjugated system. However, the C-C bond length (1.5442 $\AA$ ) and the N-N bond length $(1.4656 \AA-1.4884 \AA)$ in the molecule is slightly longer than the normal C-C $(1.54 \AA)$ or N-N bond length $(1.45 \AA)$ which may be due to the tension of the five-numbered ring and the electron withdrawing inductive effect of the nitro groups. Besides, the $\mathrm{N}-\mathrm{NO}_{2}$ bond has been verified to be the trigger bond of nitramine explosives by both experimental and theoretical studies. Generally speaking, the bond length is closely related with the bond stability: the longer the bond is, the less stable the bond is and thus, is easier broken by accidental external stimulation. It is predicted that N3-N31 bond, which is longer than N1-N25, may be acted as the trigger bond when heated or attacked. On the other hand, the C4-N1-C2 bond angle in the five-numbered ring is $112^{\circ}$ and is much bigger than the normal interior angle $108^{\circ}$. This may be caused by the steric strain between $\mathrm{NO}_{2}$ groups on the five-numbered rings. The bond angle of N1-C4-N7 is $112.84^{\circ}$ which indicates that the two five-numbered rings in the molecule are not coplanar. Finally, the bond angle of N1-C4-N7 and N3-C6-N8 $\left(112.84^{\circ}\right)$, the dihedral angle of C2-N1-C4-N7 and N3-C6-N8-N10 $\left(-116.16^{\circ}\right)$, the dihedral angle of C2-N3-C6-N8 and N1-C4-N7-N10 $\left(96.29^{\circ}\right)$ were also found to be the same and thus, it is predicted that the title compound has a centrosymmetric structure.

\section{Heat of formation and thermodynamic properties}

Heat of formation (HOF) is usually considered when a new energetic material is designed since it plays an important role in the energetic properties. HOF is always taken to be indicative of the 'energy content' of a HEDM and can be used to estimate the amount of energy released or absorbed in a chemical reaction. However, it is an extremely hazardous and difficult task to obtain the accurate HOF values for HEDMs experimentally. Hence, density functional theory and isodesmic reactions were employed jointly to calculate accurate HOF value of the title compound. Previous studies also demonstrated it as a reliable approach to calculate the accurate HOF values of energetic materials.

Table 3 lists the total energies $\left(E_{0}\right)$, thermal corrections $\left(H_{\mathrm{T}}\right)$, zero-point energies (ZPE), and HOFs of the reference compounds. Since the $\Delta H_{\mathrm{f}, \text { solid }}$ value was calculated using the Politzer approach, the related parameters such as molecular surface area $A$ (353.1), the degree of balance between negative and positive potential $v(0.07)$, the square of the variability of the electrostatic potential $\sigma_{\text {tot }}^{2}(393.1$ $\left.\mathrm{kcal} \mathrm{mol}^{-1}\right)$, and the heat of sublimation $\Delta H_{\text {Sub }}\left(11.71 \mathrm{kcal} \mathrm{mol}^{-1}\right)$ are obtained using the Multiwfn program..$^{27}$ It is obviously seen that the title compound has a high positive $\mathrm{HOF}$ value $\left(740.4 \mathrm{~kJ} \mathrm{~mol}^{-1}\right)$ which may be attributed to the large number of the energetic $\mathrm{N}-\mathrm{N}$ bonds and $\mathrm{N}-\mathrm{NO}_{2}$ groups in the ring skeleton.

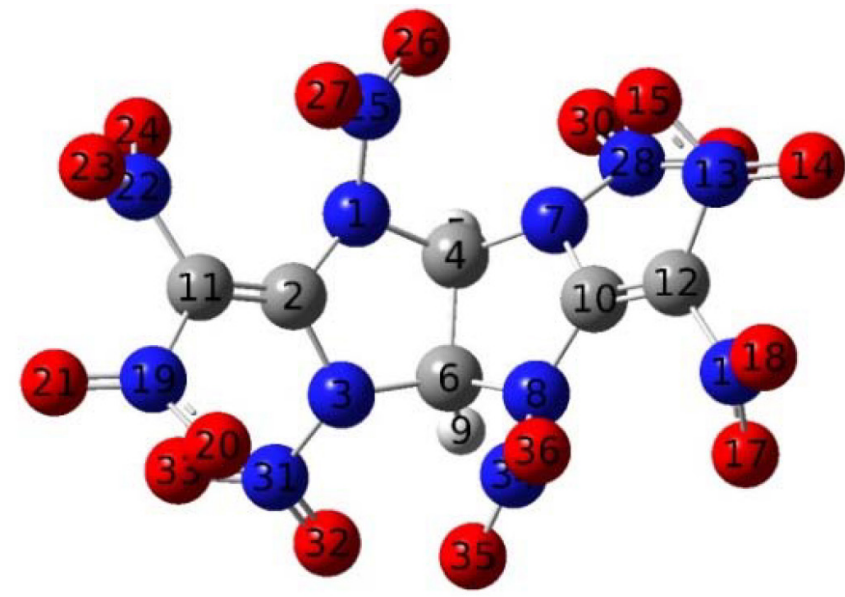

Figure 3. Molecular structure of the title compound

The IR spectrum together with their thermodynamic properties often used to analyze or identify the structure and chemical properties of a compound. Figure 4 presents the simulated IR spectra of 3,7-bis(dinitromethylene)-2,4,6,8-tetranitro-2,4,6,8-tetraazabicyclo[3.3.0]octane at B3LYP/6-31G $(d, p)$ level. It is obviously seen that there are several main characteristic regions: the

Table 2. Selected bond length, bond angle and dihedral angle of the title compound at B3LYP/6-31G $(d, p)$ level

\begin{tabular}{cccccc}
\hline Bond & Bond length/ $\AA$ & Bond & bond angle/ & Bond & dihedral angle/ \\
\hline N1-C4 & 1.4856 & C4-N1-N25 & 115.42 & C4-N1-N25-O27 & -136.62 \\
N1-C2 & 1.3937 & C4-N1-C2 & 112.32 & C4-N1-C2-C11 & -177.49 \\
C2-N3 & 1.4074 & N1-C2-C11 & 128.21 & C2-C11-N22-O23 & 32.52 \\
N3-C6 & 1.4486 & N1-C2-N3 & 107.02 & C2-C11-N19-O20 & -125.59 \\
C4-C6 & 1.5442 & C2-N3-C6 & 111.47 & N1-C2-N3-O31 & C2-N3-C6-N8 \\
N1-N25 & 1.4656 & C2-N3-N31 & 119.27 & C2-N3-N31-O32 & 159.04 \\
N3-N31 & 1.4884 & N1-C4-C6 & 102.47 & C2-N3-C6-H9 & -139.26 \\
C2-C11 & 1.3580 & C2-C11-N22 & 122.66 & C2-N1-C4-N7 & -116.16 \\
C11-N19 & 1.4674 & C2-C11-N19 & 122.17 & N3-C6-N8-N10 & -116.16 \\
C11-N22 & 1.4625 & N1-C4-N7 & 112.84 & N1-C4-N7-N10 \\
C6-H9 & 1.0871 & N3-C6-N8 & 112.84 & & 96.29 \\
\hline
\end{tabular}


Table 3. Calculated total energies $\left(E_{0}\right.$, au $)$, thermal corrections $\left(H_{\mathrm{T}}, \mathrm{kJ} \mathrm{mol}^{-1}\right)$, zero-point energies $\left(\mathrm{ZPE}, \mathrm{kJ} \mathrm{mol}^{-1}\right)$, and heats of formation $\left(\mathrm{HOFs}, \mathrm{kJ}^{\mathrm{mol}}{ }^{-1}\right)$ for the reference compounds

\begin{tabular}{ccccccc}
\hline Compound & $E_{0}$ & $\mathrm{ZPE}$ & $H_{\mathrm{T}}$ & $\Delta H_{\mathrm{f}, \text { gas }}$ & $\Delta H_{\text {sub }}$ & $\Delta H_{\mathrm{f}, \text { solid }}$ \\
\hline $\mathrm{NH}_{3}$ & -56.557769 & 0.034442 & 0.003807 & $-45.9^{\mathrm{a}}$ & & \\
$\mathrm{CH}_{4}$ & -40.524020 & 0.045026 & 0.003810 & $-74.6^{\mathrm{a}}$ & & \\
$\mathrm{NH}_{2} \mathrm{NO}_{2}$ & -261.035046 & 0.038304 & 0.004439 & $-80.9^{\mathrm{a}}$ & & \\
$\mathrm{CH}_{3} \mathrm{NO}_{2}$ & -245.013375 & 0.050043 & 0.005254 & 345.2 & 79.0 & \\
$\mathrm{C}$ & -453.6290523 & 0.167311 & 0.010011 & 789.4 & 740.4 \\
$\mathrm{D}$ & -2089.390301 & 0.184676 & 0.029665 & & 49.0 \\
\hline
\end{tabular}

${ }^{a}$ Experimental values taken from Ref. 28. ${ }^{b}$ Values taken from Ref. 29.

bands in $3100-3200 \mathrm{~cm}^{-1}$ are contributed from the $\mathrm{C}-\mathrm{H}$ stretch in the five-numbered ring; the strongest characteristic peak at around $1600-1800 \mathrm{~cm}^{-1}$ is associated with the $\mathrm{N}=\mathrm{O}$ asymmetric stretch of nitro groups; other remarkable signal ranges from 1000 to $1400 \mathrm{~cm}^{-1}$ is associated with the $\mathrm{N}-\mathrm{N}$ asymmetric stretch while the signals less than $1000 \mathrm{~cm}^{-1}$ belongs to the fingerprint area which were mainly caused by the torsion of the skeleton and the bend vibration of nitro groups.

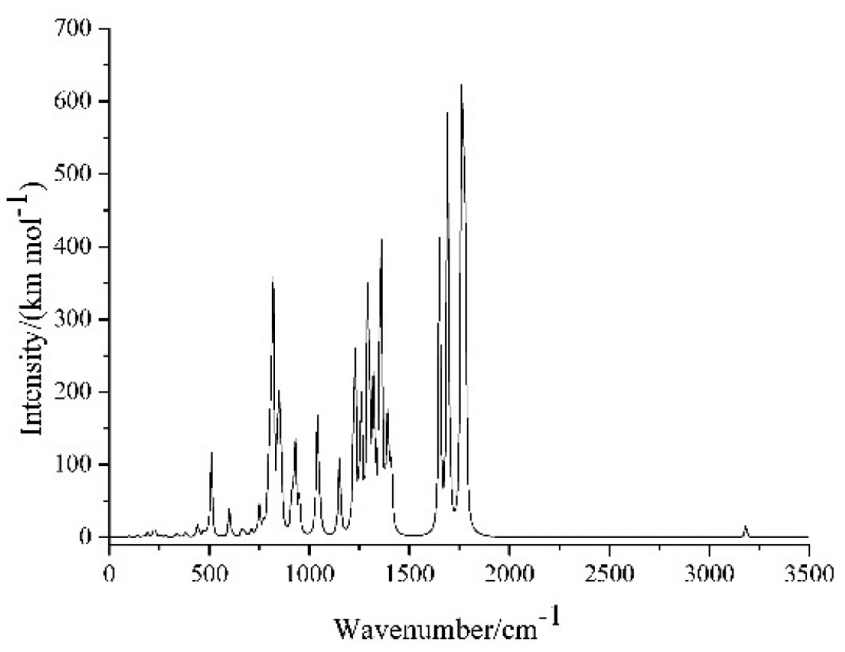

Figure 4. Simulated IR spectra of the title compound at B3LYP/6-31G(d,p) level

On the basis of vibrational analysis results and statistical thermodynamic methods, thermodynamic properties, including standard molar heat capacity $C_{p, m}^{0}$, standard molar entropy $S_{m}^{0}$ and standard molar enthalpy $H_{m}^{0}$ were evaluated and tabulated in Table 4.

Table 4. Thermodynamic properties of the title compound at different temperatures

\begin{tabular}{cccc}
\hline$T(\mathrm{~K})$ & $C_{p, m}^{0}\left(\mathrm{~J} \mathrm{~mol}^{-1} \mathrm{~K}^{-1}\right)$ & $S_{m}^{0}\left(\mathrm{~J} \mathrm{~mol}^{-1} \mathrm{~K}^{-1}\right)$ & $H_{m}^{0}\left(\mathrm{~kJ} \mathrm{~mol}^{-1}\right)$ \\
\hline 200 & 332.79 & 652.09 & 40.16 \\
300 & 435.89 & 806.97 & 78.69 \\
400 & 523.39 & 944.76 & 126.77 \\
500 & 593.54 & 1069.41 & 182.74 \\
600 & 648.08 & 1182.66 & 244.91 \\
700 & 690.08 & 1285.85 & 311.87 \\
\hline
\end{tabular}

The correlation equations between the thermodynamic functions and temperature from $200 \mathrm{~K}$ to $700 \mathrm{~K}$ were also summarized in Figure 5. From the figure, it is found that all the $C_{p, m}^{0}, S_{m}^{0}$ and
$H_{m}^{0}$ values increase evidently as the temperature increases and the gradients of $C_{p, m}^{0}, S_{m}^{0}$ decrease whereas the gradients of $H_{m}^{0}$ increases constantly. The mainly contributions to the thermodynamic functions are from the translation and rotation of molecules at low temperatures, considering that as the vibration motion is intensified at higher temperatures, there will be more contribution to the enthalpy. ${ }^{30}$ Besides, the correlation equations were expressed as follows (where $R^{2}$ is the correlation coefficients):

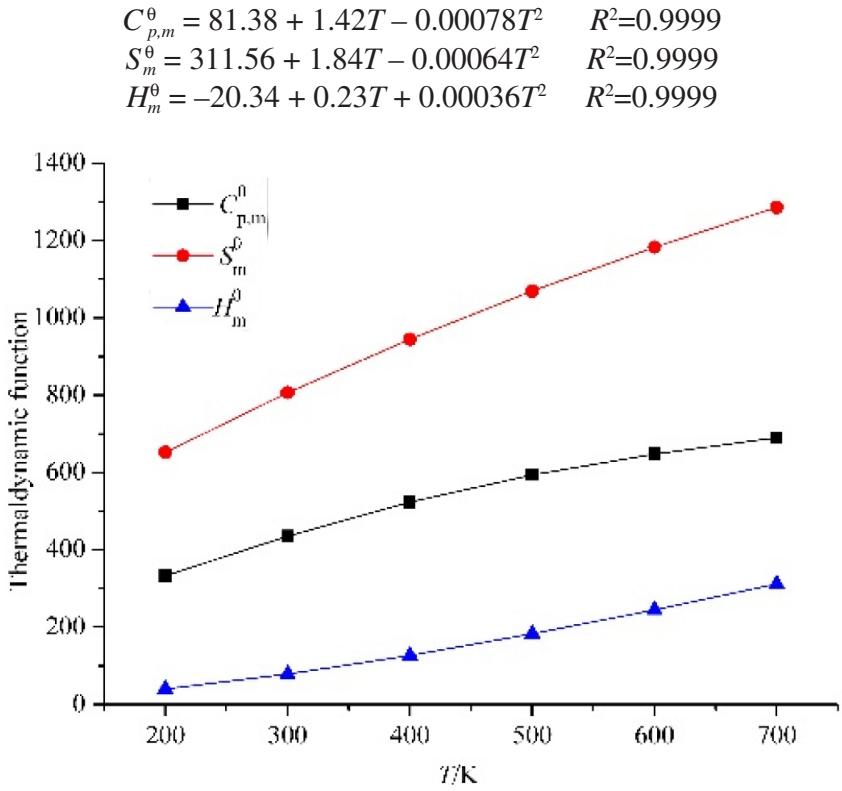

Figure 5. Relationships between the thermodynamic functions and temperature (T) for the title compound

\section{Crystal structure}

Molecular mechanics (MM) has been widely used to predict the molecular packing (crystal structure) of the energetic compounds. COMPASS,${ }^{31}$ a force field able to produce the gas- and condensed-phase properties reliably for lots of energetic materials, was used to predict the crystal structure of 3,7-bis(dinitromethylene)-2,4,6,8-tetranitro-2,4,6,8-tetraazabicyclo[3.3.0]octane. Previous studies have demonstrated it as a reliable way in predicting the molecular structure. The high-density polymorph is sorted out from the large number of potential crystal structures, and the relative lattice parameters are presented in Table 5. Obviously, it is seen that the energies of the most probable seven space groups are in the range from -137.38 to $-139.54 \mathrm{~kJ} \mathrm{~mol}^{-1}$ cell $^{-1}$ and the structure with $P 2_{1} 2_{1} 2_{1}$ symmetry has the lowest energy. Therefore, it is predicted that the title compound may tend to exist in the $P 2_{1} 2_{1} 2_{1}$ group (Figure 6). The calculated cell 
Table 5. Unit cell parameters of the possible molecular packing of the title compound

\begin{tabular}{|c|c|c|c|c|c|c|c|}
\hline Space groups & $P-1$ & $P 2_{1}$ & $P 2_{1} 2{ }_{1} 21$ & $P 2_{1} / \mathrm{c}$ & $P$ na $2_{1}$ & Pbca & $C 2 / \mathrm{c}$ \\
\hline$Z$ & 2 & 2 & 4 & 4 & 4 & 8 & 8 \\
\hline$E\left(\mathrm{~kJ} \mathrm{~mol}^{-1} \mathrm{cell}^{-1}\right)$ & -139.44 & -137.38 & -139.54 & -138.69 & -137.75 & -139.19 & -138.84 \\
\hline$a(\AA)$ & 23.39 & 11.96 & 22.03 & 19.23 & 20.13 & 17.78 & 24.47 \\
\hline$b(\AA)$ & 6.61 & 8.53 & 8.73 & 14.74 & 8.44 & 16.58 & 10.66 \\
\hline$c(\AA)$ & 7.87 & 8.07 & 8.42 & 13.49 & 9.66 & 10.95 & 23.21 \\
\hline$\alpha\left(^{\circ}\right)$ & 72.14 & 90.00 & 90.00 & 90.00 & 90.00 & 90.00 & 90.00 \\
\hline$\beta\left(^{\circ}\right)$ & 105.91 & 75.98 & 90.00 & 154.71 & 90.00 & 90.00 & 90.00 \\
\hline$\gamma\left({ }^{\circ}\right)$ & 57.42 & 90.00 & 90.00 & 90.00 & 90.00 & 90.00 & 90.00 \\
\hline
\end{tabular}

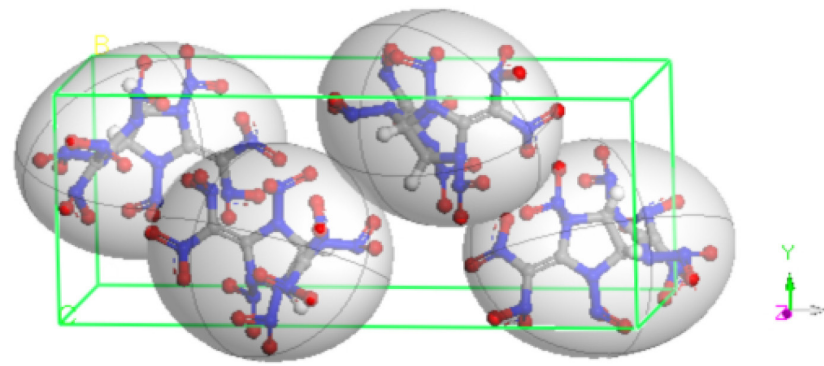

Figure 6. Simulated crystal structure of the title compound

parameters are summarized as follows: $Z=4, a=22.03 \AA, b=8.73 \AA$, $c=8.42 \AA, \alpha=90^{\circ}, \beta=90^{\circ}$ and $\gamma=90^{\circ}$, respectively.

\section{Detonation properties}

Together with the calculated density of $2.08 \mathrm{~g} \mathrm{~cm}^{-3}$ obtained using Monte Carlo method from the volume inside an electron density contour of $0.001 \mathrm{e} \mathrm{Bohr}^{-3}$, the values of detonation velocity and detonation pressure of 3,7-bis(dinitromethylene)-2,4,6,8-tetranitro-2,4,6,8-tetraazabicyclo[3.3.0]octane were listed in Table 6 . In comparison with the $\rho, D$, and $P$ values of the famous energetic material RDX and HMX, it is found that the calculated $\rho, D$, and $P$ of 3,7-bis(dinitromethylene)-2,4,6,8-tetranitro-2,4,6,8-tetraazabicyclo[3.3.0] octane $\left(\rho, 2.08 \mathrm{~g} \mathrm{~cm}^{-3} ; D, 9.77 \mathrm{~km} \mathrm{~s}^{-1}\right.$ and $\left.P, 45.9 \mathrm{GPa}\right)$ were superior to those of RDX $\left(\rho, 1.82 \mathrm{~g} \mathrm{~cm}^{-3} ; D, 8.7 \mathrm{~km} \mathrm{~s}^{-1} ; P\right.$, $34.0 \mathrm{GPa})$ and $\operatorname{HMX}\left(\rho, 1.91 \mathrm{~g} \mathrm{~cm}^{-3} ; D, 9.1 \mathrm{~km} \mathrm{~s}^{-1} ; P, 39.0 \mathrm{GPa}\right){ }^{32}$ In a word, the title compound can be considered as a potential high-energy density material according to the energy criterion for HEDMs (i.e., $\left.\rho>1.9 \mathrm{~g} \mathrm{~cm}^{-3}, D>9.0 \mathrm{~km} \mathrm{~s}^{-1}, P>40.0 \mathrm{GPa}\right) .^{33}$

Table 6. Detonation properties of the title compound, RDX and HMX

\begin{tabular}{lccc}
\hline Compound & $\rho\left(\mathrm{g} \mathrm{cm}^{-3}\right)$ & $D\left(\mathrm{~km} \mathrm{~s}^{-1}\right)$ & $P(\mathrm{GPa})$ \\
\hline Title compound & 2.08 & 9.77 & 45.9 \\
RDX & $1.78^{\mathrm{a}}\left(1.82^{\mathrm{b}}\right)$ & $8.87^{\mathrm{a}}\left(8.75^{\mathrm{b}}\right)$ & $34.67^{\mathrm{a}}\left(34.0^{\mathrm{b}}\right)$ \\
HMX & $1.88^{\mathrm{a}}\left(1.91^{\mathrm{b}}\right)$ & $9.28^{\mathrm{a}}\left(9.10^{\mathrm{b}}\right)$ & $39.19^{\mathrm{a}}\left(39.10^{\mathrm{b}}\right)$ \\
\hline
\end{tabular}

aTheoretical values are calculated at the B3LYP/6-31 G(d,p) level. ${ }^{34}$ bxperimental values are taken from Ref. 33 .

\section{Electronic structure and stability}

Analysis of the molecular orbital of an energetic material is necessary since it can provide useful information on its physical and chemical properties. Previous studies have also proved that the larger the energy gap $\left(\Delta E_{\text {Luмо-номо }}\right)$ of the structure, the lower the reactivity of a compound. ${ }^{35}$ The calculated energy of HOMO, LUMO and their energy gap of the title compound are $-8.53 \mathrm{eV},-4.34 \mathrm{eV}$ and $4.19 \mathrm{eV}$, respectively. It indicates that the title compound may have a lower reactivity. Figure 7 illustrates the highest occupied molecular orbital (HOMO, a), the lowest unoccupied molecular orbital (LUMO, b) and molecular electrostatic potentials (MEP, c) of 3,7-bis(dinitromethylene)-2,4,6,8-tetranitro-2,4,6,8-tetraazabicyclo[3.3.0]octane. From the figure, it is obviously found that title molecule has a symmetric structure and the symmetry delocalizes ๘ electron cloud density of system, which makes the stability of the compound increase. It also can be seen that the molecule has 125 HOMOs and 126 LUMOs, and most of the HOMO and LUMO levels are of 2-fold degenerate. In view of the MEP, in which the colors range from -0.023 to 0.023 Hartree with red denoting the most negative potential and blue denoting the most positive potential, negative potentials appear to be distributed mostly on the $-\mathrm{NO}_{2}$, specially the $=\mathrm{C}\left(\mathrm{NO}_{2}\right)_{2}$ groups at the end of the bicycle-skeleton; the positive ranges mainly characterize at the center of the bicycle-skeleton, which attributes some stabilization to the compound. This result is consistent with the stability criterion that proposed by Klapotke et al. ${ }^{36}$

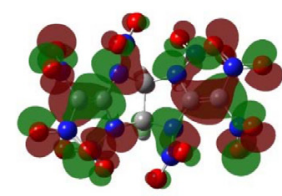

a

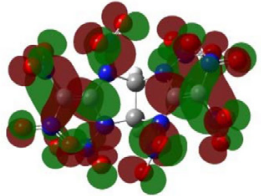

b

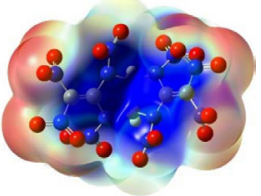

c
Figure 7. HOMO (a), LUMO (b), and MEP (c) of the title compound

Additionally, Politzer et al..$^{37}$ proposed that $h_{50}$, which can be calculated via Equation (8), is also an important parameter to predict the impact sensitivity of an energetic material. The calculated impact sensitivity $(59 \mathrm{~cm})$ shows that the title compound is more stable than those of HMX $(29 \mathrm{~cm})$ and RDX $(26 \mathrm{~cm})$.

$$
h_{50}=a \sigma_{+}^{2}+b \frac{\sigma_{+}^{2} \sigma_{-}^{2}}{\left(\sigma_{+}^{2}+\sigma_{-}^{2}\right)^{2}}+c
$$

where $a, b$ and $c$ are constants and can be obtained from Ref. 37; the quantities $\sigma_{+}^{2}, \sigma_{-}^{2}$ are indicators of the strengths and variabilities of the positive and negative surface potentials, respectively.

\section{Stability under moisture}

Previous studies have shown that compounds which contain dinitrourea segment are easier to decompose to other products under 
moisture. This is because the carbon atom located in dinitrourea segment is more electropositive due to the inductive effect of nitro group and $p-\pi$ conjugation effect of carbonyl group and thus, these types of compounds are easier to be attacked by nucleophilic reagents to form other products. In order to compare the moist stability of the title compound with TNGU, natural bond orbital (NBO) charges on the carbonyl-carbon atom was analyzed based on the hydrolysis mechanism at B3LYP/6-31G $(d, p)$ level (Figure 8). From the figure, it is obviously that positive charges on the carbonyl-carbon atom of the title compound (0.37) is less than that of TNGU (0.83) and thus TNGU is easier to be attacked by water to form other products. On the other hand, $\mathrm{C}=\mathrm{C}\left(\mathrm{NO}_{2}\right)_{2}$ segment is large than $=\mathrm{O}$ which may prevent carbonyl-carbon being attacked by $\mathrm{H}_{2} \mathrm{O}$. Therefore, it can be concluded that water-resistance of the title compound is better than that of TNGU both from the point of view of electronic and the space steric effects.

\section{Synthetic routes}

From the above-discussions, it is seen that the title compound possesses superior detonation properties compared to those of RDX and HMX which makes it a new candidate as high-energy density material with a number of potential applications. Thus, a possible synthetic route was proposed according to the retro-synthetic analy$\operatorname{sis}^{38}$ (Figure 9).

\section{CONCLUSIONS}

In this paper, a new high-energy density material (HEDM) 3,7-bis(dinitromethylene)-2,4,6,8-tetranitro-2,4,6,8-tetraazabicyclo[3.3.0] octane was designed and investigated theoretically. The following conclusions can be drawn:

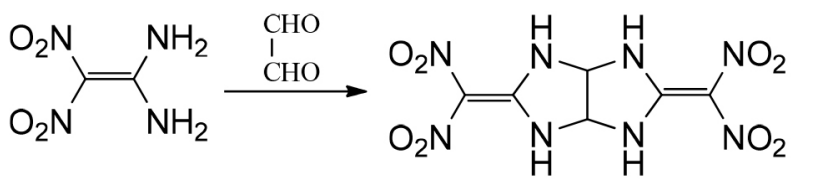

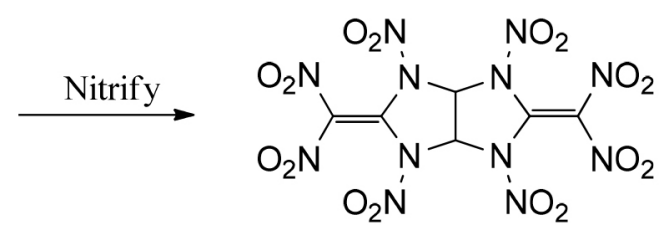

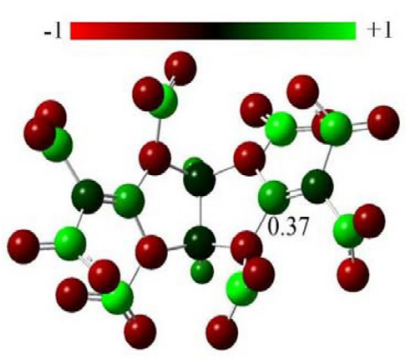

a

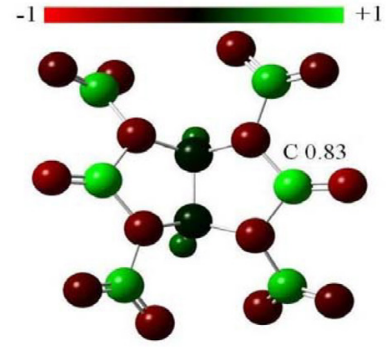

b
Figure 8. NBO charges of the title compound (a) and TNGU (b)

(1) 3,7-Bis(dinitromethylene)-2,4,6,8-tetranitro-2,4,6,8tetraazabicyclo[3.3.0] octane has a centrosymmetric structure and N3-N31 has the longest bond length which may be considered as the trigger bond when heated or attacked.

(2) The title compound has a high positive heat of formation $\left(740.4 \mathrm{~kJ} \mathrm{~mol}^{-1}\right)$ and the thermodynamic properties such as the standard molar heat capacity $C_{p, m}^{0}$, standard molar entropy $S_{m}^{0}$ and standard molar enthalpy $H^{0}{ }_{m}$ increase evidently as the temperature increases.

(3) The molecular packing prediction indicates that the title compound belongs to $P 2{ }_{1} 2_{1} 2_{1}$ space group, with cell parameters $Z=4, a=$ $22.03 \AA, b=8.73 \AA, c=8.42 \AA, \alpha=90^{\circ}, \beta=90^{\circ}$ and $\gamma=90^{\circ}$.

(4) The title compound has superior detonation properties $(D$, $9.77 \mathrm{~km} \mathrm{~s}^{-1} ; P, 45.9 \mathrm{GPa}$ ) to those of RDX and HMX. It meets the requirements and can be considered as a potential high-energy density material.

(5) The energy gap ( $\left.\Delta E_{\text {LUмо-номо }}\right)$ and the molecular electrostatic potentials reveal that the title compound is consistent with the stability criterion.

Figure 9. Possible synthetic route of the title compound

\section{REFERENCES}

1. Sikder, A. K.; Sikder, N.; J. Hazard. Mater. 2004, 112, 1.

2. Zhao, G. Z.; Lu, M.; Quim. Nova 2013, 36, 513.

3. Jin, X. H.; Hu, B. C.; Lu, W.; Gao, S. J.; Liu, Z. L.; Lv. C. X.; RSC Adv. 2014, 4, 6471 .

4. Ma, C. M.; Liu, Z. L.; Yao. Q. Z.; Can. J. Chem. 2014, 92, 803.

5. Pagoria, P. F.; Lee, G. S.; Mitchell, A. R.; Schmidt, R. D.; Thermochim. Acta. 2002, 384, 187.

6. Hudson, R. J.; Zioupos, P.; Gill, P. P.; Propellants, Explos., Pyrotech. 2012, 37, 191.

7. Landenberger, H. B.; Matzger, A. J.; Cryst. Growth Des. 2012, 12, 3603.

8. Bayat, Y.; Zeynali, V.; J. Energ. Mater. 2011, 29, 281.

9. Qiu, L.; Xiao, H. M.; J. Hazard. Mater. 2009, 164, 329.

10. Anniyappan, M.; Talawar, M. B.; Gore, G. M.; Venugopalan, S.; Gandhe, B. R.; J. Hazard. Mater. 2006, 137, 812.

11. Klapötke, T. M.; Sabaté, C. M.; Chem. Mater. 2008, 20, 3629.

12. Chi, W. J.; Li, L. L.; Li, B. T.; Wu, H. S.; J. Mol. Model. 2012, 18, 3695.

13. Frisch, M. J.; Trucks, G. W.; Schlegel, H. B.; Scuseria, G. E.; Robb, M. A.; Cheeseman, J. R.; Zakrzewski, V. G.; Montgomery, J. A.; Strat- mann, R. E.; Burant, J. C.; Dapprich, S.; Millam, J. M.; Daniels, A. D.; Kudin, K. N.; Strain, M. C.; Farkas, O.; Tomasi, J.; Barone, V.; Cossi, M.; Cammi, R.; Mennucci, B.; Pomelli, C.; Adamo, C.; Clifford, S.; Ochterski, J.; Petersson, G. A.; Ayala, P. Y.; Cui, Q. K.; Morokuma, D. K.; Malick, A. D.; Rabuck, K.; Raghavachari, J. B.; Foresman, J. C.; Ortiz, J. V.; Baboul, A. G.; Stefanov, B. B.; Liu, G.; Liashenko, A.; Piskorz, P.; Komaromi, I.; Gomperts, R.; Martin, R. L.; Fox, D. J.; Keith, T.; Al-Laham, M. A.; Peng, C. Y.; Nanayakkara, A.; Gonzalez, C.; Challacombe, M.; Gill, P. M. W.; Johnson, B.; Chen, W.; Wong, M. W.; Andres, J. L.; Gonzalez, C.; Head-Gordon, M.; Replogle, E. S.; Pople, J. A.; Gaussian, Inc.: Pittsburgh, PA. Gaussian 03, 2003.

14. Ravi, P.; Tewari, S. P.; Struct. Chem. 2012, 23, 487.

15. Jin, X. H.; Hu, B. C.; Jia, H. Q.; Liu, Z. L.; Lv, C. X.; Quim. Nova 2014, $37,74$.

16. Becke, A. D.; J. Chem. Phys. 1992, 97, 9173.

17. Lee, C.; Yang, W.; Parr, R. G.; Phys. Rev. B 1988, 37, 785.

18. Sviatenko, L. K.; Gorb, L.; Hill, F. C.; J. Comput. Chem. 2013, 34, 1094.

19. Dill, J. D.; Pople, J. A.; J. Chem. Phys. 1975, 62, 2921.

20. Glendening, E. D.; Landis, C. R.; Weinhold, F.; Comput. Mol. Sci. 2012, 2,1 . 
21. Wu, Q.; Pan, Y.; Zhu, W. H.; Xiao, H. M.; J. Mol. Model. 2013, 19, 1853

22. Wu, Q.; Zhu, W. H.; Xiao, H. M.; J. Mol. Model. 2013, 19, 2945.

23. Atkins, P. W.; Physical chemistry, $2^{\text {nd }}$ ed., Oxford University Press: Oxford, 1982.

24. Politzer, P.; Ma, Y.; Lane, P.; Concha, M. C.; Int. J. Quantum Chem. 2005, 105, 341.

25. Kamlet, M. J.; Jacobs, S. J.; J. Chem. Phys. 1968, 48, 23.

26. Politzer, P.; Martinez, J.; Murray, J. S.; Concha, M. C.; Toro-Labbé, A.; Mol. Phys. 2009, 107, 2095.

27. Lu, T.; Chen, F.; J. Comp. Chem. 2012, 33, 580

28. Fan, X. W;. Ju, X. H.; J. Comp. Chem. 2008, 29, 505.

29. Wilcox, C. F.; Zhang, Y. X.; Bauer, S. H.; J. Mol. Struct.: THEOCHEM 2000, 528, 95 .

30. Zhao, G.; Lu, M.; Struct. Chem. 2013, 24, 139.
31. Sun, H.; J. Phys. Chem. B 1998, 102, 7338 .

32. Liu, H.; Wang F.; Wang, G. X.; Gong, X. D.; J. Phys. Org. Chem. 2012, 26,30 .

33. Xiao, H. M.; Xu, X. J.; Qiu, L.; Theoretical design of high energy density materials, Science Press: Beijing, 2008.

34. Zhou, H.; Ma, Z; Wang, J.; Wang D.; Def. Technol. 2014, 10, 384.

35. Chi, W. J.; Li, L. L.; Li, B. T.; Wu, H. S.; J. Mol. Model. 2013, 19, 571.

36. Hammerl, A.; Klapotke, T. M.; Nöth, H.; Warchhold, M.; Holl, G.; Propellants, Explos., Pyrotech. 2003, 28, 165.

37. Pospísili, M.; Vávra, P.; Concha, M. C.; Murray, J. S.; Politzer. P.; J. Mol. Model. 2010, 16, 895

38. Smith, M. B.; March, J.; March's Advanced Organic Chemistry, Wiley: Hoboken, 2001. 